\title{
MERCURY AND SELENIUM RETENTION IN FLY ASHES: INFLUENCE OF UNBURNED PARTICLE CONTENT
}

\author{
M. Antonia López-Antón, Mercedes Díaz-Somoano, Patricia Abad-Valle \\ and M. Rosa Martínez-Tarazona* \\ Instituto Nacional del Carbón (CSIC). C/ Francisco Pintado Fe, 26, 33011, Oviedo, \\ Spain
}

*Corresponding author. Telephone +34 985119090; Fax +34 985297662

E-Mail address: rmtarazona@incar.csic.es 


\begin{abstract}
Mercury and selenium are present as trace elements in coal and may be emitted to the environment in gas phase during coal conversion processes or be partially retained on the fly ashes. The present work explores the possibility that selenium may contribute to mercury capture in fly ashes in two different situations: firstly the power station itself, in order to evaluate the influence of typical working conditions, and secondly in a fixed bed of fly ashes enriched with Se, in order to study the capture of mercury in more severe conditions. It was found that the presence of selenium in fly ashes may improve their capacity to capture mercury. However, in the four fly ashes of different origin studied, selenium is not the most important component for mercury retention. In fact, the presence of selenium in fly ash samples enriched in unburned carbon does not have any significant effect on mercury retention.
\end{abstract}

Keywords: mercury; selenium; fly ash

\title{
Introduction
}

Mercury and selenium compounds are classified as trace elements of environmental concern [1]. During coal combustion the mercury and selenium species present in coal are evaporated and may be emitted in gas phase [2]. Coal-fired power plants are cited as one of the largest anthropogenic sources of mercury and selenium into the environment [3]. Regulations for mercury emission from coal combustion are now a matter of main concern not only in USA [1], but also in Europe [4]. Although less attention has been paid to regulations regarding selenium which is a nutritional element at low concentrations, environmental bodies, such as the EPA, will probably introduce measures to reduce the emissions of this element in the near future [1]. The 
capture of trace elements in fly ashes and fly ash components and the relationship between fly ash particle size and trace element retention have been discussed in a number of works [5-7]. However, the interactions between selenium and mercury in coal combustion plants have not been sufficiently studied [8].

There are compelling reasons to consider the emissions of mercury and selenium together, which may be summarized as follows i) $\mathrm{Hg}$ and Se are both found in fish, which is the primary pathway for the harmful effects of $\mathrm{Hg}$ on health [9], ii) Se has been shown to suppress $\mathrm{Hg}$ methylation in aqueous systems, which is a necessary step to prevent the effects of $\mathrm{Hg}$ on health [10] iii) the ability of selenium compounds to decrease the toxic action of mercury has been established in several species of mammals, birds and fish [10-11]. Selenium and mercury influence each other's bioavailability, toxicology and remediation, the protective effect of Se appearing to depend on the formation of mercury selenide (HgSe) [12].

With respect to coal combustion, both $\mathrm{Se}$ and $\mathrm{Hg}$ are emitted from coal power plants mainly as vapour but are also captured in fly ashes in low proportions [13]. Considered individually, the quantity of selenium and mercury retained or captured in fly ashes may vary from coal to coal, depending on the characteristics of the ashes and process conditions, including gas cleaning systems such as FGD. The precise mechanism by which trace elements are retained in fly ashes is not completely understood. In some works, it is accepted that the unburned coal particles present in fly ashes are responsible for, or may significantly influence, the retention of mercury species [14-16]. However, the possibility of mutual Hg-Se-fly ash interactions has not yet been explored and $\mathrm{Hg}$-Se capture by carbon particles in fly ash needs to be investigated more thoroughly. For this reason, in the present work mercury and selenium retention in fly ashes was studied in two different situations: i) in the power 
station itself, in order to evaluate the working conditions typical of coal combustion and ii) in a fixed bed of fly ashes enriched with Se in order to study the capture of mercury in more severe conditions. The study was focused on four fly ash samples of different origin and characteristics.

\section{Experimental}

Four fly ash samples from different power stations which burned coals of different rank and nature were used in this study. Three of them were obtained in pulverized coal combustion power plants (PCC), while the fourth was taken from a fluidized coal combustion power plant (FBC) that uses limestone in its bed. The fuels burned in these power stations were coal blends of different origin. In one of the power stations the blend contained high rank coals (the fly ash was denoted as CTA). In another, bituminous coals were used (CTL), while in the third, sub bituminous coals were employed (CTES). The FBC plant burned a mixture of bituminous coal and coal wastes of high calorific value. This sample was named CTP. The four power stations have electrostatic precipitators as particle control devices but none of them is fitted with flue gas desulphurization systems. Fly ashes from the precipitator were sampled in all cases. The small quantities of particles that are not retained and were carried out with flue gases were not considered in this study.

In the first part of the work, size fractionation of the fly ashes was carried out by dry and wet sieving. Different fractions were separated for each sample in order to obtain sample fractions enriched in unburned particles with a high yield. The unburned carbon particle content in each fraction was estimated as loss of ignition (LOI), and the mercury content was analyzed by using an Automatic Mercury Analyser (AMA). 
Selenium was determined by inductively coupled plasma mass spectrometry (ICP-MS). A morphological study was carried out by Scanning Electron Microscopy (SEM); the crystalline species were identified by X-ray diffraction (XRD) and the BET surface area was measured by the volumetric adsorption of nitrogen at $77 \mathrm{~K}$. In the second part of the study, the fly ash samples (CTA, CTL, CTES and CTP) and three fractions of these samples $(\mathrm{CTA}>150 \mu \mathrm{m}, \mathrm{CTL}>100 \mu \mathrm{m}$ and CTES $>200 \mu \mathrm{m})$, enriched in unburned coal particles, were used as sorbents for mercury and selenium retention. In the CTP sample the unburned particles were homogeneously distributed among the different particles and for this reason only the raw CTP sample was used in this study.

The experimental device used for the selenium retention experiments at laboratory scale consisted of a glass reactor fitted with an internal and external tube and heated by two different furnaces (Fig. 1). Selenium in gas phase was obtained by the evaporation of solid $\mathrm{Se}^{0}$. The temperature of evaporation, $400^{\circ} \mathrm{C}$, was calibrated to obtain a selenium concentration in gas phase of $0.4 \mu \mathrm{g} \mathrm{ml}{ }^{-1}$. The fly ash bed and the element source were placed inside the same internal tube but heated separately in the two furnaces. The selenium was carried by air in vapour phase through the sorbent bed at a flow rate of $0.5 \mathrm{~L} \mathrm{~min}^{-1}$. The temperature of the sorbent was $120^{\circ} \mathrm{C}$. Any of the element that could not be retained in the sorbent bed was captured in impingers containing $\mathrm{HNO}_{3} 0.5 \mathrm{~N}$. The amount of selenium retained was determined by analysing the fly ashes post-retention by means of ICP-MS after extraction using $60 \%(\mathrm{v} / \mathrm{v})$ $\mathrm{HNO}_{3}$.

The experimental device used for retaining mercury in the fly ashes enriched with selenium was similar to that previously described (Fig. 2). The fly ash bed was placed inside the same internal tube and was heated to $120^{\circ} \mathrm{C}$. In this case, the $\mathrm{Hg}^{0}$ in gas phase was obtained from a permeation tube, and it was passed through the sorbent 
bed in an air atmosphere at $2.5 \mathrm{~L} \mathrm{~min}^{-1}$. The mercury concentration in gas phase was $1.9810^{-5} \mu \mathrm{g} \mathrm{ml}{ }^{-1}$. A continuous mercury emission monitor (UT 3000) was used to monitor the mercury. As in the first reactor, any mercury that could not be retained in the sorbent bed was captured by impingers containing $1 \mathrm{~N} \mathrm{KCl,} 5 \% \mathrm{HNO}_{3} / 10 \% \mathrm{H}_{2} \mathrm{O}_{2}$ and $4 \% \mathrm{KMnO}_{4} / 10 \% \mathrm{H}_{2} \mathrm{SO}_{4}$.

\section{Results and discussion}

The mercury and selenium content in each fly ash fraction was determined in order to evaluate the distribution of mercury and selenium compounds (Fig. 3). The concentrations of both elements varied in the different samples and fractions. Mercury concentrations were lower than $2 \mu \mathrm{g} \mathrm{g}^{-1}$ and selenium reached more than $8 \mu \mathrm{g} \mathrm{g}^{-1}$. In Fig. 3 it can be observed that no relationships between the particle size and mercury or selenium content were found in the fly ashes obtained from PCC. However, in CTP, obtained from FBC, the mercury was concentrated in the smallest size particles. A possible explanation for this might be that the lower combustion temperature in the fluidized bed combustion plant may benefit mercury condensation on the smallest size particles. As regards their morphology, it is well known that fly ashes from PCC are mainly formed by microspheres (Fig. 4a), while the fly ash particles from FBC are irregular in shape (Fig. 4b). A parallel behaviour between selenium and mercury content in the fly ash fractions is observed in the CTP and CTES samples (Fig. 3). Consequently the possibility that selenium and mercury may play a mutual role in each other is capture cannot be ruled out in the case of the fly ash obtained from FBC and in PCC where sub bituminous coals are employed. 
In order to evaluate the relation of mercury and selenium to the unburned carbon, the mercury and selenium contents of the fractions separated from the ashes were compared with the LOI value which is considered to be equivalent to the unburned carbon concentration (Fig. 5). Mercury and selenium behave differently in each of the samples studied. In CTL the highest mercury concentration was present in the fraction that had low unburned carbon content $(10 \%)$, whereas selenium was present in the fraction of highest unburned carbon $(40 \%)$. In the CTA sample, the mercury content increased slightly with LOI to $10.2 \%$, reaching a maximum value of $0.84 \mu \mathrm{g} \mathrm{g}^{-1}$. Thereafter it decreased, although the LOI increased. The highest selenium concentration in CTA was present in the fraction, whose LOI value was $22.1 \%$, while the lowest selenium concentration was present in the fraction whose LOI value was $22.4 \%$ (Fig. 5). In the size fractions of the CTES fly ash, which were taken from a power station that burned coal blends containing subbituminous coals, there was a very low mercury content. The maximum mercury concentration was found in a fraction of intermediate LOI value (20-30\%). A similar behavior was observed in the case of selenium. Finally, although in the CTP sample the highest mercury content was exhibited by the fractions with $6.4 \%$ of LOI, and the highest selenium content by the fractions with $9.5 \%$ of LOI (Fig. 5), a correlation between mercury and selenium content was observed in most fractions of this sample, although no correlation was found with unburned content. These findings indicate that there is no relationship between unburned carbon and mercury or selenium capture in the fly ashes studied.

The possibility of modifying the conditions to favour interactions between Se and $\mathrm{Hg}$ was also explored by comparing the capacity of all fly ashes and selected fractions enriched in unburned particles with that of the samples enriched in selenium, in fixed beds. In the fractions enriched in unburned particles the LOI content may be as 
high as $40 \%$ (Fig. 5). The surface area and LOI value of these fly ashes are presented in Table 1. An increase in the surface area of the CTA, CTL and CTES fractions can be observed as the unburned carbon particle content increases but there is no apparent correlation between the unburned particles and surface area when compared to the four raw fly ashes (Table 1). Although the differences in surface area are not significant compared to those of porous materials, according to the results of this and other works [17], they are significant enough to have an influence on mercury capture.

The mineral phases identified by XRD in these four fly ashes were different. The only crystalline species identified in CTA was quartz, whereas in CTL, lime and aluminosilicates (mullite) were also found. In CTES, quartz, lime, mullite, anhydrite and ferric sulfate were identified. In the fly ash obtained from FBC quartz, anhydrite, calcite, illite and ferric oxide were detected. These results indicate that aluminosilicates and compounds of calcium and iron are present in higher proportions in CTL, CTES and CTP than in CTA.

The mercury adsorption curves for the original fly ashes and fractions enriched in unburned carbon and for the samples enriched in different quantities of selenium after the adsorption experiments are given in Fig. 6. The horizontal discontinuous line represents the background and the vertical discontinuous line represents the breakthrough time $(90 \mathrm{~min})$. The breakthrough time was defined as the time necessary for the original fly ash sample to reach maximum retention. This breakthrough time was used with the aim of achieving the mercury retention capacity in a reasonable time period. Although this fact influences the absolute retention capacity for each of the materials tested, it is valuable as a means of differentiating between the fly ashes tested as sorbents in similar conditions. The concentration of mercury retained (retention 
capacity) was calculated as the area above the curve between the background and the breakthrough time.

The retention capacity values are presented in Table 2 together with the concentrations of selenium. The original fly ashes contain the selenium that was captured in the power station, whereas the enriched samples include the selenium adsorbed in the retention experiments. In the original fly ashes and fractions, the concentrations were lower than $6.11 \mu \mathrm{g} \mathrm{g}^{-1}$, while in the samples enriched in selenium the concentrations were between 84.5 and $212 \mu \mathrm{g} \mathrm{g}^{-1}$. If the whole samples are considered without making any distinction as to the source, no relationships can be observed between the selenium content and mercury capture. As an example, the retention capacity of mercury in the CTPSe sample, which contains $212 \mu \mathrm{g} \mathrm{g}^{-1}$ of selenium, is $3.90 \mu \mathrm{g} \mathrm{g}^{-1}$, whereas in the sample CTL $>100$ which contains $6.09 \mu \mathrm{g} \mathrm{g}^{-1}$ it is $5.20 \mu \mathrm{g} \mathrm{g}^{-1}$. These results indicate that, although the presence of selenium influences mercury capture, the mercury-selenium reactions are not the dominant mechanisms for mercury retention. However, when samples from the same fly ash are compared (Fig. 6), the retention of mercury is higher in the fly ash samples enriched with selenium. The exception is the CTL sample where the presence of high quantities of selenium does not significantly modify the capture of mercury. Moreover, the kinetics of mercury adsorption in each fly ash is different (Fig. 6). In each group of samples prepared from the same fly ash a decrease in the adsorption rate is observed in the fly ashes impregnated with selenium.

The theoretically possible reactions between $\mathrm{Hg}$ and $\mathrm{Se}$ in experimental conditions at $120^{\circ} \mathrm{C}$ in an air atmosphere have been formulated below [1-4]. These reactions might be expected to be favored in the case of fly ashes which have adsorbed selenium in a high proportion. 


$$
\begin{aligned}
& \mathrm{Hg}(\mathrm{g})+\mathrm{Se}=\mathrm{HgSe} \\
& \mathrm{Hg}(\mathrm{g})+\mathrm{SeO}_{2}+\mathrm{O}_{2}(\mathrm{~g})=\mathrm{HgSeO}_{4} \\
& 2 \mathrm{HgO}(\mathrm{g})+2 \mathrm{Se}=2 \mathrm{HgSe}+\mathrm{O}_{2}(\mathrm{~g}) \\
& \mathrm{HgO}(\mathrm{g})+\mathrm{SeO}_{2}+1 / 2 \mathrm{O}_{2}(\mathrm{~g})=\mathrm{HgSeO}_{4}
\end{aligned}
$$$$
\mathrm{K}=7.09 \times 10^{9}
$$$$
\mathrm{K}=6.62 \times 10^{13}
$$$$
\mathrm{K}=3.45 \times 10^{18}
$$$$
\mathrm{K}=1.73 \times 10^{13}
$$

However, when comparing the behaviour of the fractions enriched with unburned carbon particles, it can observed that the differences between mercury retention in the fly ashes with a high unburned carbon content (CTL $>100$; CTA $>150$ and CTES $>200$ ), and the same samples enriched with selenium (CTL $>100$ Se; $\mathrm{CTA}>150 \mathrm{Se}$ and $\mathrm{CTES}>200 \mathrm{Se}$ ) are lower than when the original fly ashes (CTL, CTA, CTES and CTP) are compared with the same samples but with higher quantities of Se (CTL Se, CTA Se, CTES Se and CTP Se) (Table 2). Consequently the effect of selenium is more noticeable in the original fly ashes than in the fractions enriched in unburned carbon particles. In Fig. 6 and Table 2, it can be observed that mercury retention in the CTL fly ash increased from 1.56 to $5.20 \mu \mathrm{g} \mathrm{g}^{-1}$ when it was enriched with the unburned carbon, whereas it increased from 1.56 to $4.96 \mu \mathrm{g} \mathrm{g}^{-1}$ when it was enriched with unburned carbon and selenium. The difference between 5.20 and 4.96 may be attributed to the uncertainty of the method of calculation and to the fact that the presence of selenium in the fly ash samples enriched in unburned particles does not modify the retention capacity of mercury. Thus it appears that mercury capture not only depends on the selenium content; the nature of the unburned particles and the characteristics of the fly ashes also need to be considered.

\section{Conclusions}


In the four fly ashes studied in this work, no correlation could be established between the selenium or mercury content and the unburned carbon content and only in the case of the fly ash obtained from a Fluidized Bed Combustion (FBC) plant a correlation between selenium and mercury content with the particle size was observed. Nevertheless, it should be noted that in the fly ash obtained from the pulverized coal combustion (PCC) plant in which sub bituminous coals were employed (CTES), and in the CTP fly ash, the selenium and mercury behaviour was parallel.

When fly ashes are used as a fixed bed and the contact time between the fly ash and mercury in vapor phase increases, the presence of selenium enhances mercury retention. However, in the case of fly ashes enriched in unburned carbon particles which have a better retention capacity for mercury capture, the retention of mercury is not significantly increased by the presence of selenium: the presence of selenium in the fly ashes improves mercury retention but is not the most important component.

\section{Acknowledgments}

The results of this work were obtained as part of the projects PPQ2001-2359-C02-02 and CTM2004-04252.CO2-02/TECNO

\section{References}

[1]U.S. Environmental Protection Agency, http://www.epa.gov/

[2]Clarke LB, Sloss LL. Trace elements-emissions from coal combustion and gasification. IEA Coal Research. 1992, IEACR/49 111pp, London, 1992

[3]Sloss LL, Smith IM. Trace elements emissions IEA Coal Research CCC/34 2000, $83 \mathrm{pp}$

[4] $\underline{\text { http://europa.eu.int/comm/environment/chemicals/mercury/index.htm }}$ 
[5]Arditsoglou A, Petaloti Ch, Terzi E, Sofoniou M, Samara C. Size distribution of trace elements and polycyclic aromatic hydrocarbons in fly ashes generated in Greek lignite-fired power plants. Sci Total Environ 2004; 323:153-67.

[6]Spears DA, Martínez-Tarazona MR. The fate of trace elements and bulk minerals in pulverized coal combustion in a power station. Fuel Process Technol 1996; 47:79-92

[7]Wadge A, Hutton M, Peterson PJ. The concentrations and particle size relationships of selected trace elements in fly ashes from U.K. Coal-Fired Power plants and refuse incinerator. Sci Total Environ 1986; 54:13-27.

[8]Saroff L, Lipfert FW, Moskowitz PD. Mercury-selenium interactions in the environment. Proc Int Tech Conf Coal Util Fuel Syst 1996; 21:777-88.

[9]Lima APS, Sarkis JES, Shihomatsu HM, Muller RCS. Mercury and selenium concentrations in fish samples from Cachoeira do PiriaMunicipality, ParaState, Brazil. Environ Res 2005; 97:236-44.

[10]Wang WX, Wong RSK, Wang J, Yen YF. Influences of different selenium species on the uptake and assimilation of $\mathrm{Hg}$ (II) and methylmercury by diatoms and green mussels. Aquatic Toxicol 2004; 68:39-50.

[11]Dietz R, Riget F, Born EW. An assessment of selenium to mercury in Greenland marine animals. Sci Total Environ 2000; 245:15-24.

[12]Raymond LJ, Ralston NVC. Mercury: selenium interactions and health implications. Seychelles Medical and Dental Journal, Special Issue, Vol. 7, No 1, November 2004

[13]Davidson RM, Clarke LB. Trace elements in coal IEA Coal Research 1996, IEAPER/21 60pp, London 1996.

[14]Serre SD, Silox GD. Adsorption of elemental mercury on the residual carbon in coal fly ash. Ind Eng Chem Res 2000; 39:1723-30. 
[15]Hower JC, Maroto-Valer MM, Taulbee D N, Sakulpitakphon T. Mercury capture by distinct fly ash carbon forms. Energ Fuel 2000; 14:224-226.

[16]Li Z, Luo X, Hwang JY. Unburned carbons from fly ash for mercury adsorption II: Adsorption Isotherms and Mechanisms. J Min Mat Cgara Eng 2002; 1:79-96.

[17]Dunham GE, DeWall RA, Senior CL. Fixed-bed studies of the interactions between mercury and coal combustion fly ash. Fuel Process Technol 2003; 82:197-213. 
Table 1.-Lost of ignition (LOI) and surface area (A) of the fly ash samples

\begin{tabular}{l|cc}
\hline & LOI (\%) & $\mathbf{A ~ ( \mathbf { ~ m } ^ { 2 } \mathbf { g } ^ { - \mathbf { 1 } } )}$ \\
\hline CTA & 5.7 & 1.6 \\
CTA $>$ 150 & 22.4 & 4.2 \\
\hline CTL & 5.6 & 4.1 \\
CTL $>$ 100 & 35.4 & 23.9 \\
\hline CTES & 2.0 & 1.9 \\
CTES> 200 & 17.8 & 13.4 \\
\hline CTP & 3.8 & 6.7 \\
\hline
\end{tabular}


Table 2. Retention capacity of mercury in samples with different selenium content.

\begin{tabular}{lcc}
\hline & $\begin{array}{c}\text { Se } \\
\text { concentration } \\
\left(\boldsymbol{\mu g ~ g ~}^{-1}\right)\end{array}$ & $\begin{array}{c}\text { Hg } \\
\text { retention } \\
\left(\boldsymbol{\mu g ~ g ~}^{-1}\right)\end{array}$ \\
\hline CTL & 6.11 & 1.56 \\
CTL Se & 84.5 & 2.16 \\
CTL $>100$ & 6.09 & 5.20 \\
CTL $>100$ Se & 102 & 4.96 \\
\hline CTA & 3.89 & 1.38 \\
CTA Se & 94.6 & 4.02 \\
CTA $>150$ & 1.27 & 1.12 \\
CTA $>150$ Se & 94.3 & 2.40 \\
\hline CTES & 4.22 & 1.28 \\
CTES Se & 100 & 4.60 \\
CTES $>200$ & 4.85 & 1.00 \\
CTES $>200$ Se & 84.2 & 1.74 \\
\hline CTP & 5.18 & 1.00 \\
CTP Se & 212 & 3.90 \\
\hline
\end{tabular}




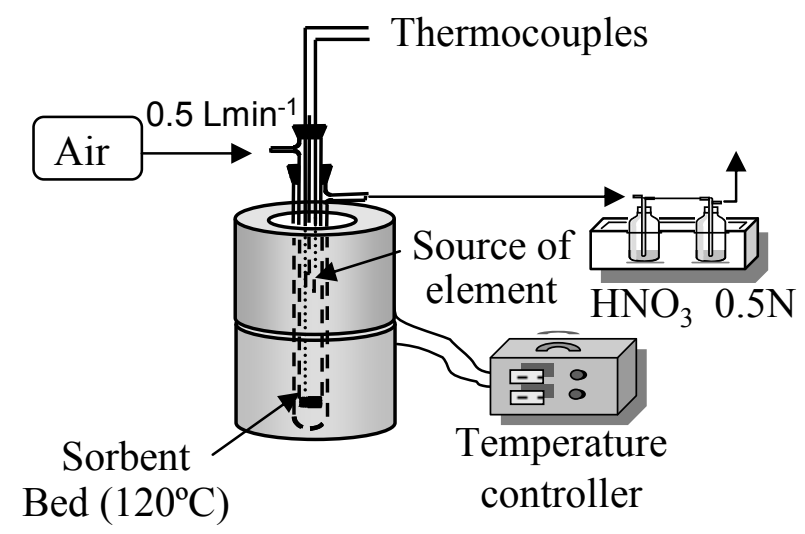

Fig. 1. Schematic diagram of the experimental device for selenium retention 


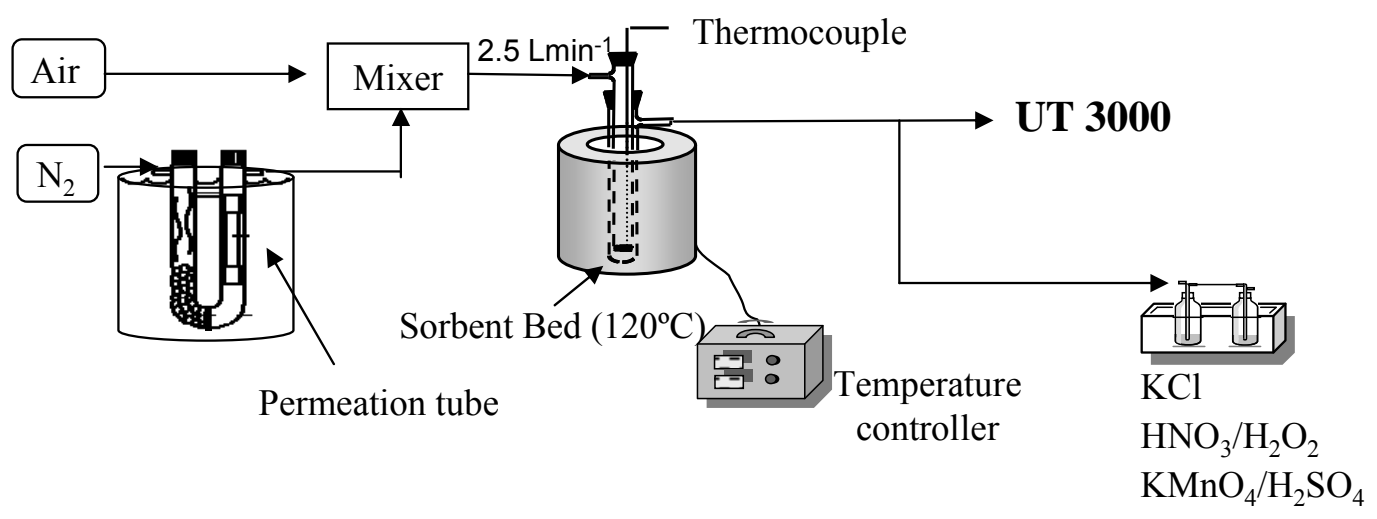

Fig. 2. Schematic diagram of the experimental device for mercury retention 

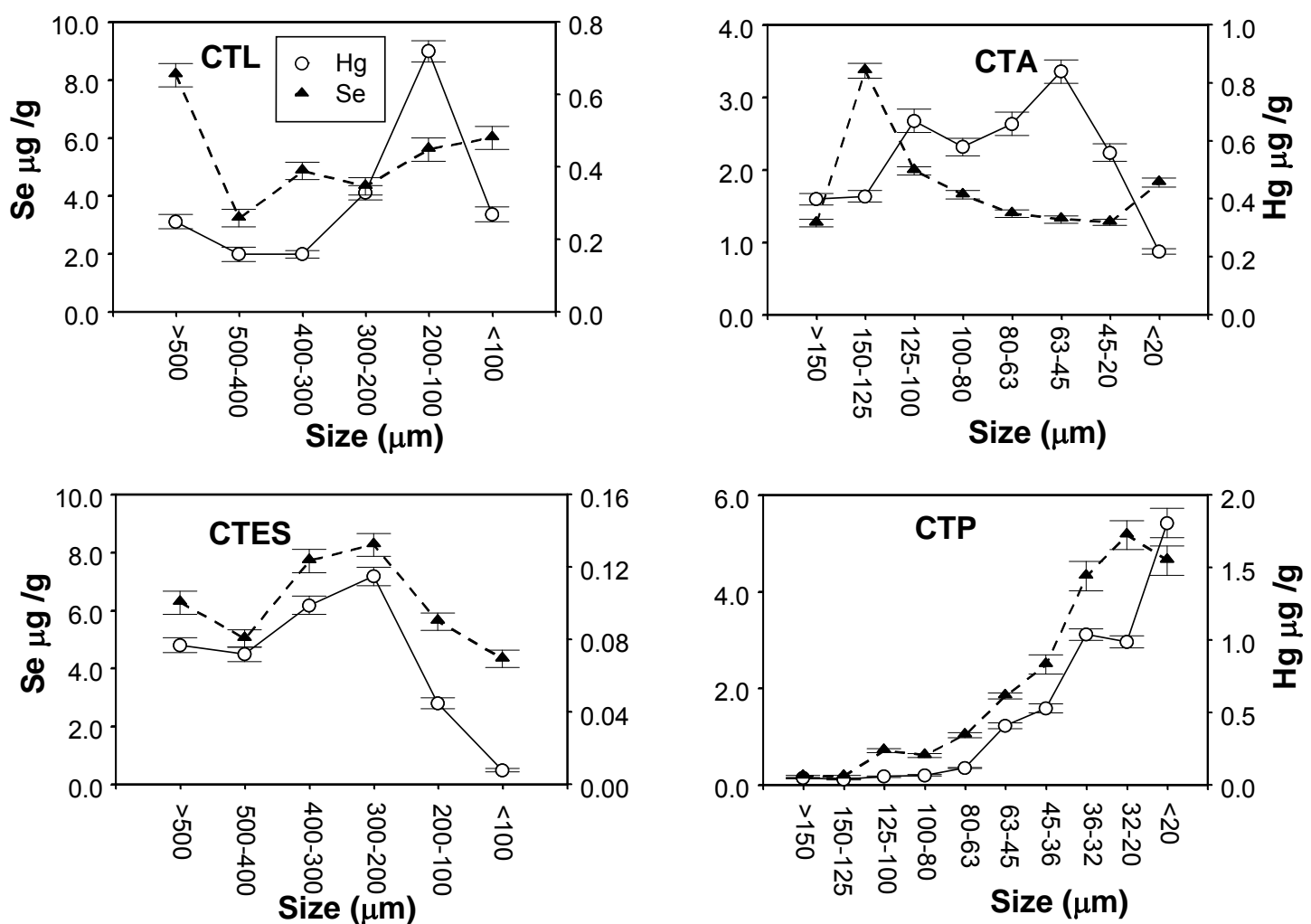

Fig 3. Mercury and selenium content in the size fractions of different fly ashes 


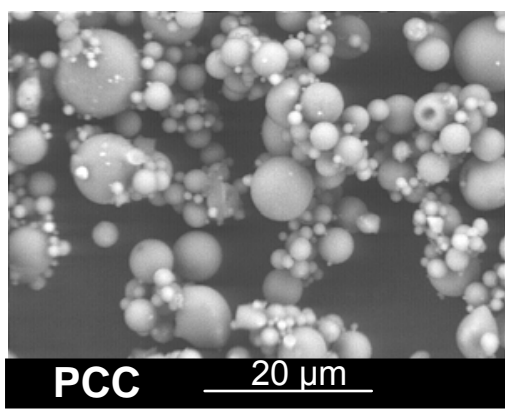

(a)

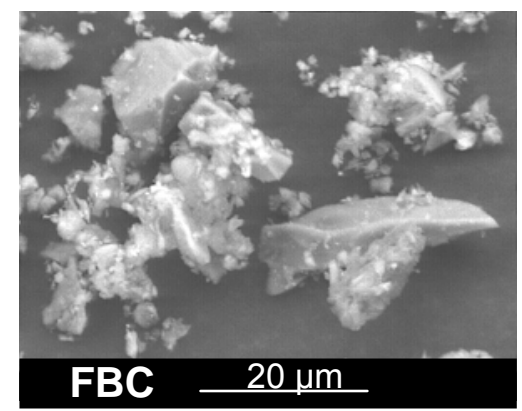

(b)

Fig. 4. SEM micrographs of the fly ashes obtained from pulverized coal combustion power plants (a) and from a fluidized coal combustion power plant (b) 

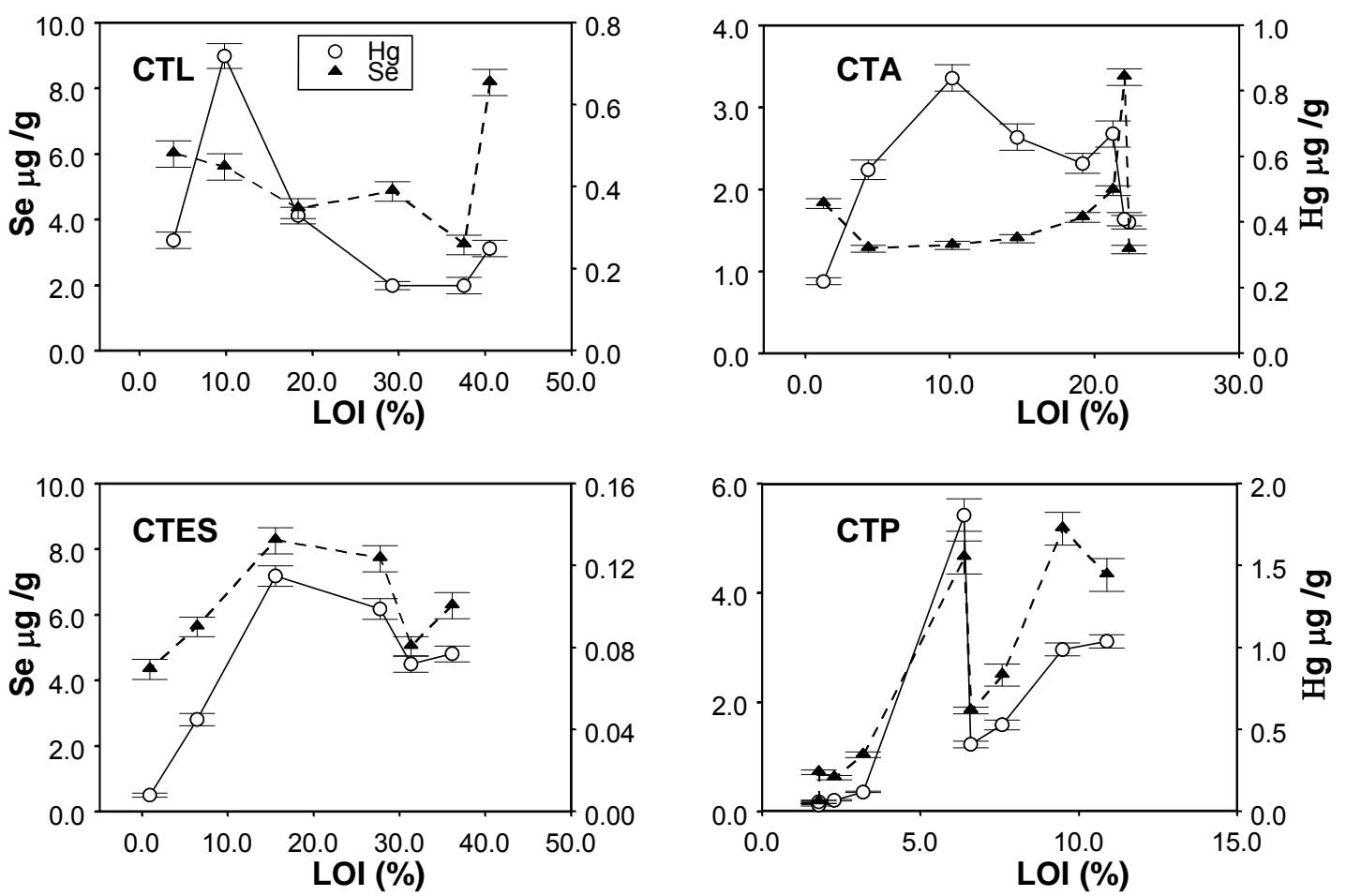

Fig. 5.-Unburned content (LOI) versus mercury and selenium content in different fly ashes 

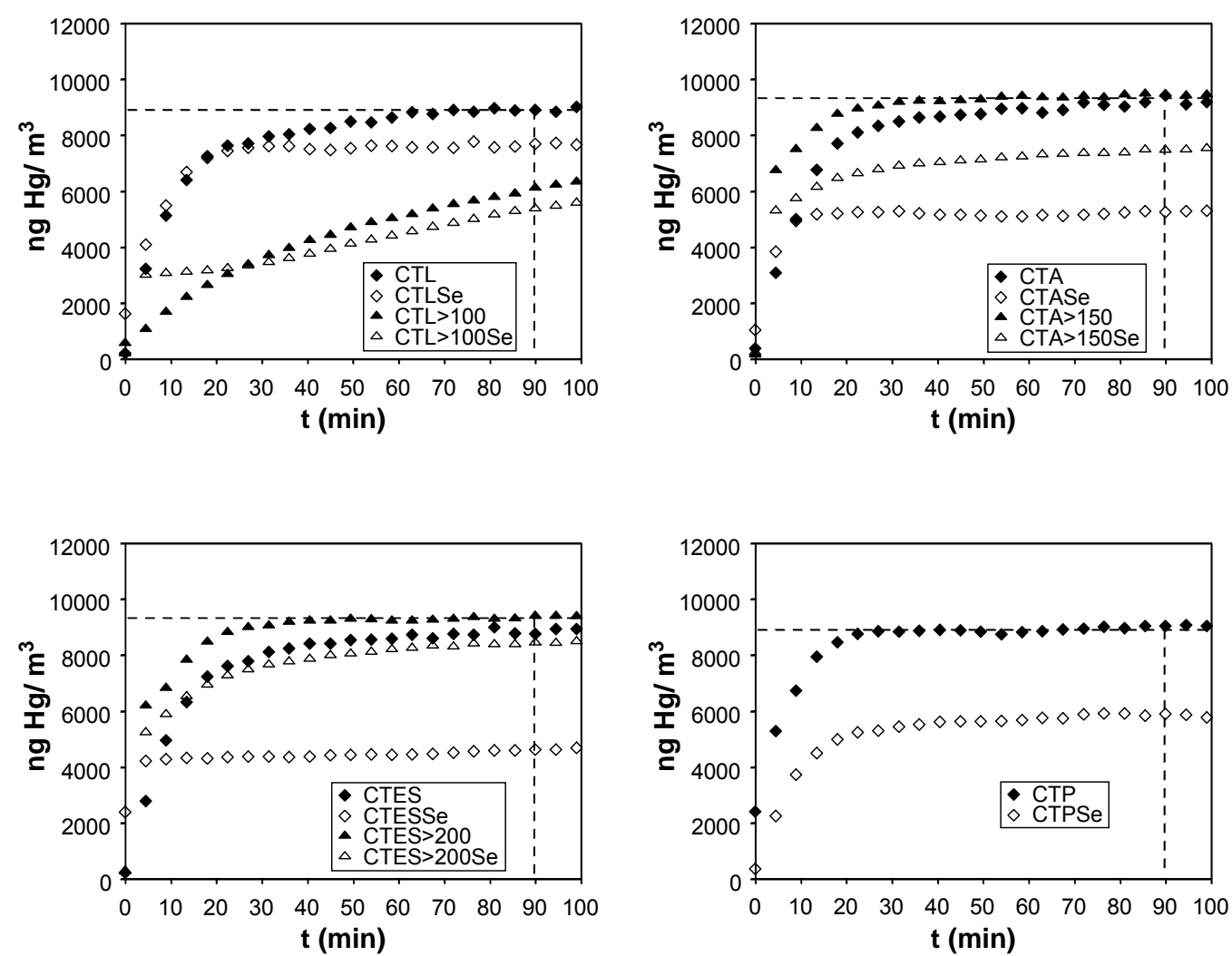

Fig. 6. Curves of mercury adsorption for the different fly ashes 